\title{
Performance Analysis of circULar Ring Slot Antenna using HFSS
}

\author{
M. Jyothi haneesha ${ }^{1}$, Siddaiah $P^{2}$, K.Y. Srinivas ${ }^{3}$ \\ Student, Wireless \& Mobile communications (ECE), Mallareddy Institute of Technology and Science ${ }^{1}$ \\ PRINCIPAL, Dept., of ECE in ANU college of engineering and technology, Acharya Nagarjuna University, Guntur ${ }^{2}$ \\ Associate Professor, Department of ECE in Mallareddy Institute of Technology and Science ${ }^{3}$

\begin{abstract}
A circular ring slot antenna (CRSA) with microstrip feeding technique is analysed at $2.45 \mathrm{GHz}$ frequency. In order to suppress additional harmonics produced by the ring slot pattern in wide range nearly 3 to $8 \mathrm{GHz}$, a defected ground structure (DGS) is integrated into the CSRA. The proposed antenna is analysed and simulated mainly for the wireless sensor network applications. This antenna is simulated by the High Frequency Structure Simulator (HFSS). Analysing the proposed antenna and simulated results on return loss, radiation pattern and gain.
\end{abstract}

Keywords: Circular Ring slot Antenna (CRSA), Defected ground structure (DGS), High Frequency Structure Simulator (HFSS) v 14, harmonic suppression.

\section{INTRODUCTION}

Wireless technology provides less expensive alternative and a flexible way for communication. Antenna is one of the most important elements of the wireless communication. One of the types of antenna is microstrip patch antenna. Microstrip technique is a planar technique used to produce lines conveying signals and antenna coupling such lines and radiated waves. It uses patches formed on the top surface of the thin substrate separating them from a conductive layer from the bottom surface of the substrate and consisting a ground for the line or the antenna. Microstrip antennas are particularly used as active antennas. Active antenna consists of active circuits integrated with antenna elements and feeding circuits which results a monolithic substrate. Thus provides compatibility with integrated circuits and easy to install on grid surface.

By adding filters generally either low pass or band pass filters between the active and passive components we can filter the unwanted harmonics but this increases complexity and makes circuit bulky. To suppress the unwanted harmonics, techniques of loading an additional tuning stub [1] and multiple shorting pins [2] into a patch antenna have been introduced earlier. But these are capable only to suppress only single harmonic mode. To suppress harmonics in wider range, the techniques of photonic band gap (PBG) [3] [4] and defected ground structure (DGS) [5][6] have been introduced. PGB technique requires periodic slot etched into the ground layer. But the usage of DGS which requires simple slot structures ( $\mathrm{H}$ - shaped, U or inverted U-shaped, L-shaped) [5] [6] is very flexible to eliminate wide range harmonic suppression.

In this communication a method of loading an inverted Ushaped DGS [7] into the ring slot of a microstrip-fed CRSA antenna is proposed. By integrating the DGS with the circular ring slot, harmonic suppression over 3 to 8 $\mathrm{GHz}$ can be achieved. By integrating DGS into the ring slot will reduces the usage of external cascading filter circuit. A detail of antenna design is described below.

\section{ANTENNA DESIGN}

The evolution of proposed slot antenna with harmonic suppression is given in fig-1. It is the combination of two simple structures those are microstrip feed CSRA and DGS.

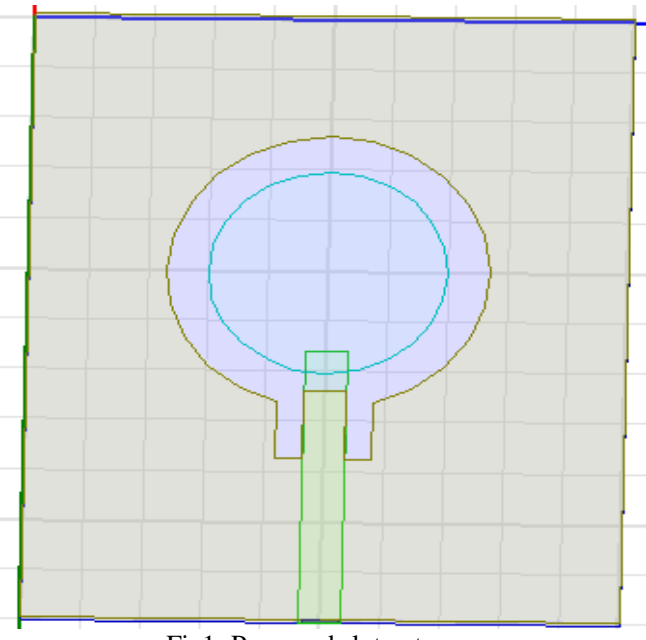

Fig1: Proposed slot antenna

The dimensions of the substrate [Width $\times$ Length $\times$ Height] are $60 \mathrm{~mm} \times 50 \mathrm{~mm} \times 0.8 \mathrm{~mm}$. The substrate used is FR4 substrate whose relative permittivity is 4.4 and tangent loss of 0.02 .

The dimensions of the CRSA and DGS are given as follows:

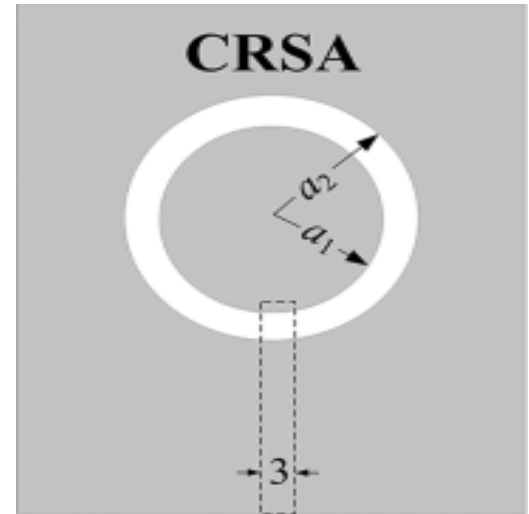

Fig 2(a): Structures of CRSA 
The inner radius $\mathrm{a} 1=10 \mathrm{~mm}$ and outer radius $\mathrm{a} 2=$ Designed CRSA with DGS is shown below: $13.5 \mathrm{~mm}$ and these are calculated by the formula:

$$
f_{0} \approx c / \pi(a 1+a 2) \times \sqrt{\varepsilon_{r}+1 / 2 \varepsilon_{r}}
$$

Where $\mathrm{c}=$ Speed of the light in free space.

$\varepsilon_{r}=$ Relative permittivity of the substrate $=4.4$ $\pi(a 1+a 2)=$ circumference of the angular ring slot antenna.

The main aim of this CSRA is to induce a fundamental mode at approximately $2.4 \mathrm{GHz}$ band.

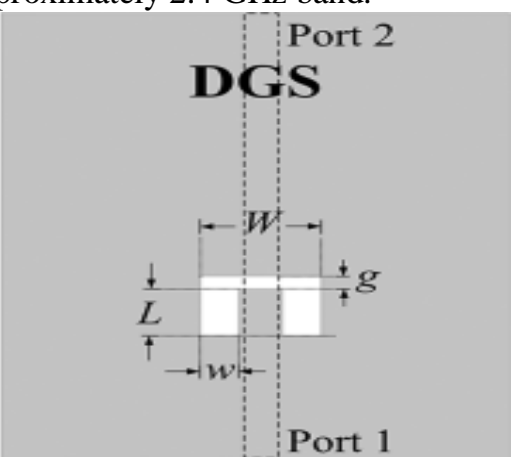

Fig 2(b): Structures of DGS

The specifications of the horizontal section of DGS are $\mathrm{L}=$ $5 \mathrm{~mm}, \mathrm{w}=2.25 \mathrm{~mm}$ and the vertical section of DGS are $\mathrm{W}=8 \mathrm{~mm}, \mathrm{~g}=0.5 \mathrm{~mm}$. The width of the feed line is taken as $3 \mathrm{~mm}$ and the length of the feed is $27 \mathrm{~mm}$.

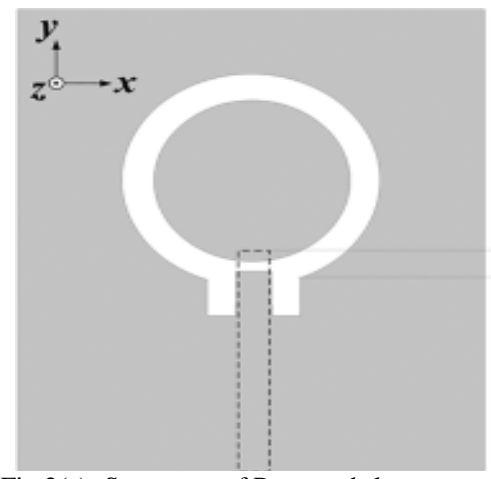

Fig 2(c): Structures of Proposed slot antenna

Simulation using High Frequency Structure Simulator (HFSS) was performed on proposed antenna and CRSA. Designed CRSA is shown below:

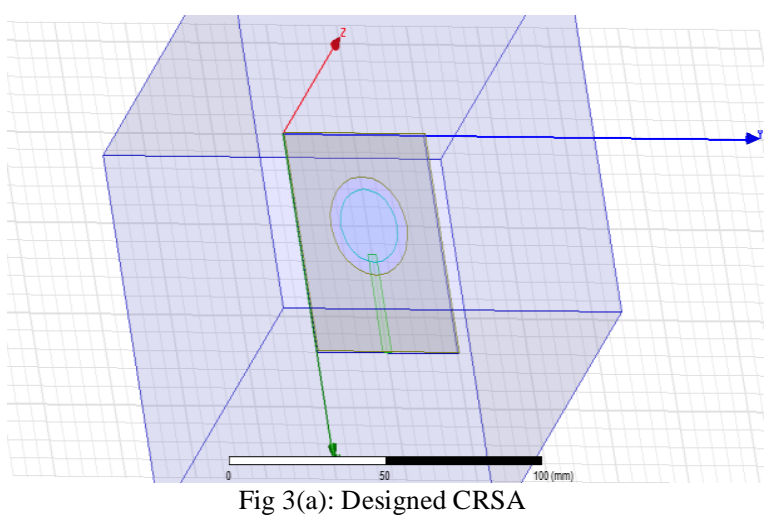

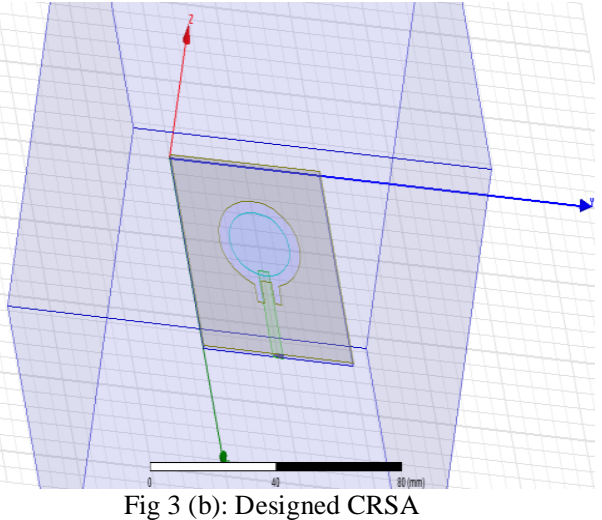

The simulated Electric and magnetic field distributions are given below:
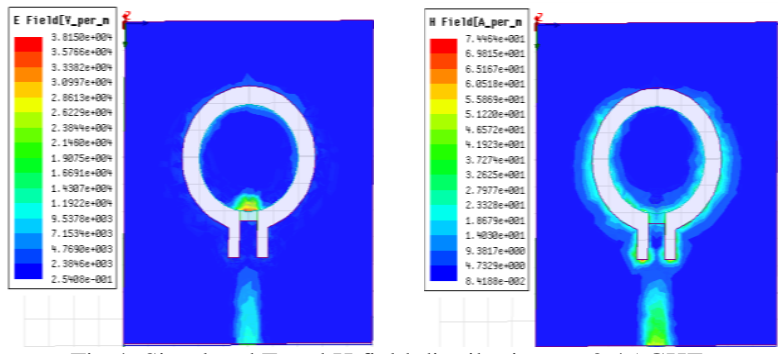

Fig 4: Simulated $\mathrm{E}$ and $\mathrm{H}$ field distributions at $2.45 \mathrm{GHZ}$

III. MEASURED RESULTS

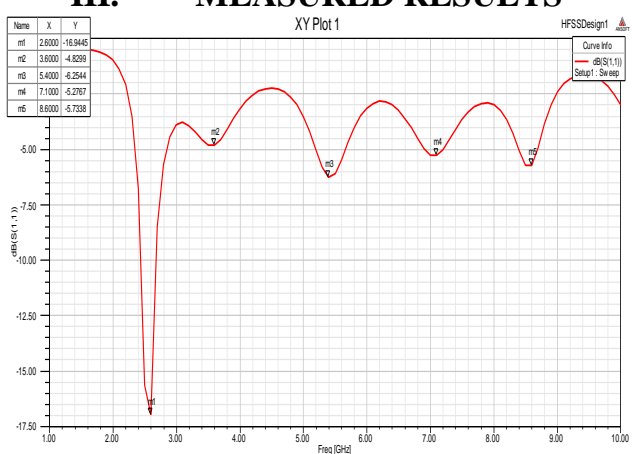

Fig 5: Fig 5: Simulated $S_{11}$ for CSRA

In CSRA the mode- $1(\mathrm{~m} 1)$ occurred at $2.6 \mathrm{GHz}$ frequency. The other four harmonics are occurred at frequencies 3.6 $\mathrm{GHz}$ (mode-2), 5.4GHz (mode-3), $7.1 \mathrm{GHz}$ (mode-4) and $8.6 \mathrm{GHz}$ (mode-5).

By integrating DGS with CRSA the harmonics are suppressed in a wide range. In the obtained result nearly 5 to $8 \mathrm{GHz}$ band is suppressed. By varying the feed position and width we can get the initial mode frequency at 2.4 $\mathrm{GHz}$ because WLANs are mainly applicable at $2.4 \mathrm{GHz}$ only. This result is shown below:

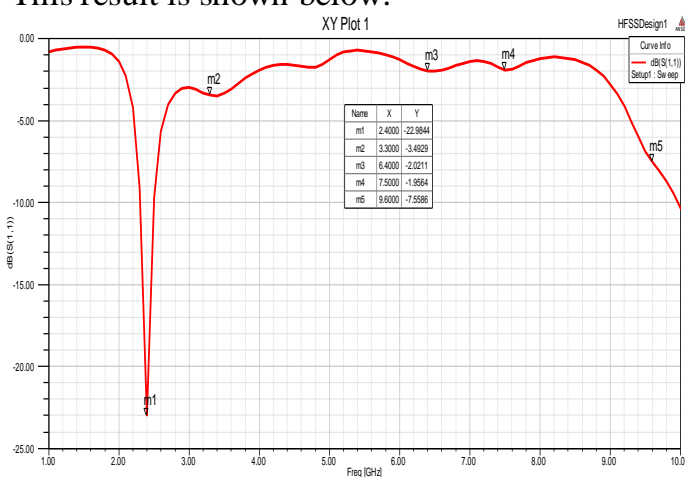

Fig 6: Simulated $S_{11}$ for proposed antenna (Return Loss) 
The proposed antenna will not affect mode- 1 at $2.4 \mathrm{GHz}$ which satisfies the standard value of wireless sensor networks. The harmonic at Mode-m3 is reduced as much as $3 \mathrm{~dB}$. The simulated $10 \mathrm{~dB}$ impedance bandwidth of the proposed antenna was between 2.3 to $2.5 \mathrm{GHz}$.

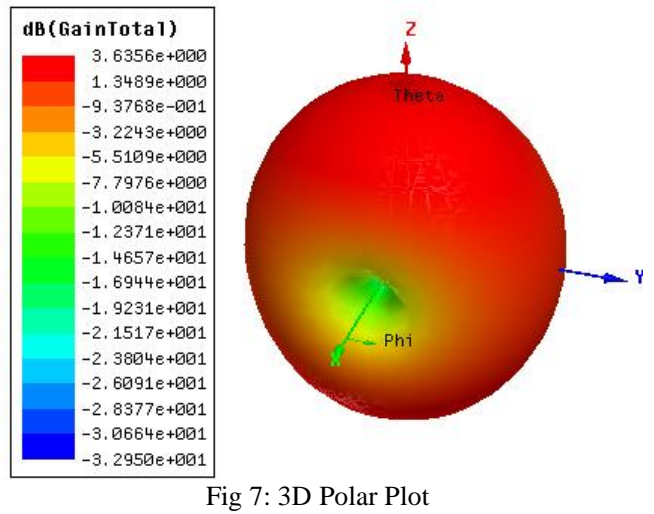

From the above 3D Polar plot the over all gain obtained is $3.6356 \mathrm{~dB}$.

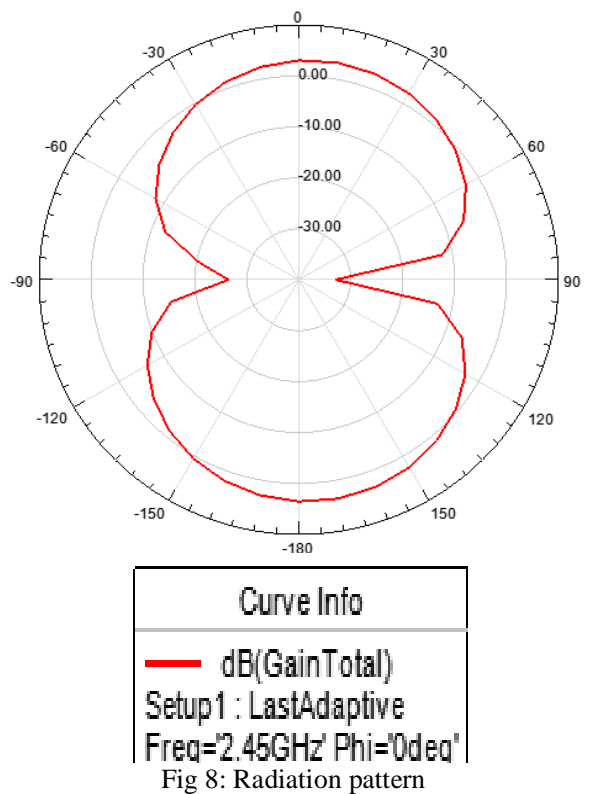

IV. CONCLUSION

This study provides an insight in determining the performance of CSRA with and without DGS. A fundamental mode can exhibit a $10-\mathrm{dB}$ impedance bandwidth between 2.3 and $2.5 \mathrm{GHz}$ with an operating frequency of $2.4 \mathrm{GHz}$. From this result it is observed that CRSA with DGS is applicable in wireless sensor networks such as WPANs and WLANs.

\section{REFERENCES}

[1] F. R. Hsiao, T. W. Chiou, and K. L. Wong, "Harmonic control of asquare microstrip antenna operated at the $1.8 \mathrm{GHz}$ band," in Proc. Microwave.Conf. Asia-Pacific, Aug. 2001, pp. 1052-1055.

[2] V.Radisic, S.T.Chew,Y.Qian,andT.Itoh,"High efficiency power amplifier integrated with antenna," IEEE Microw. Guided Wave Lett.,vol. 7, no. 2, pp. 39-41, Feb. 1997.

[3] Y. Horii and M. Tsutsumi, "Harmonic control by photonic bandgap on microstrip patch antenna," IEEE Microw. Guided Wave Lett.,vol.9, no. 1, pp. 13-48, Jan. 1999.

[4] A.S.Andrenko,Y.Ikeda,andO.Ishida,"ApplicationofPBGmicrostrip circuits for enhancing the performance of high-density substrate patch antennas," Microw. Opt. Technol. Lett., vol. 32, no. 5, pp. 340-344, Mar. 2002.
Y.J.Sung,M.Kim,andY.S.Kim,"Harmonicsreductionwithdefected ground structure for a microstrip patch antenna," IEEE Antennas Wireless Propag.Lett., vol. 2, pp. 111-113, 2003.

[6] S. Biswas, D. Guha, and C. Kumar, "Control of higher harmonics and their radiation in microstrip antennas using compact defected Ground structures," IEEE Trans. Antennas Propag., vol. 61, no. 6, pp. 3349-3353, Jun. 2013.

[7] D. J. Woo, T. K. Lee, J. W. Lee, C. S. Pyo, and W. K. Choi, "Novel U-slot and V-slot DGSs for band stop filter with improved Qfactor,'IEEE Trans. Microw. Theory Tech., vol. 54, no. 6, pp. 2840-2847, Jun. 2006.

\section{BIOGRAPHIES}

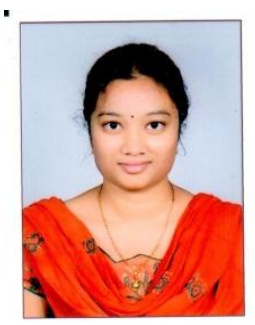

M. Jyothi Haneesha obtained B.Tech degree in (ECE) Electronics and Communication Engineering from Mallineni lakshmaiah women's engineering college in 2012. she Pursuing M.Tech (wireless and Mobile Communication Engineering),ECE at Mallareddy institute of technology and science,

Secunderabad, India.

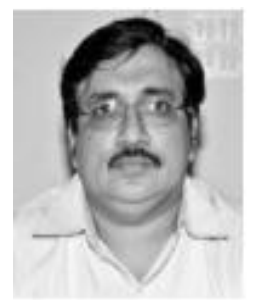

Dr. P Siddaiah obtained B.Tech degree in Electronics and communication engineering from JNTUA College of engineering in 1988. He received his M.Tech degree from SV University Tirupathi. He did his Ph.D program in JNTU Hyderabad. He is the Chief Investigator for several outstanding Projects sponsored by Defence Organizations, AICTE, UGC\& ISRO. He is currently working as Professor \& PRINCIPAL, Department of ECE in University College of Engineering and Technology, Acharya Nagarjuna University, Guntur, India. He has taught a wide variety of courses for UG \& PG students and guided several projects. Several members successfully completed their Ph.D under his guidance. Several members pursuing their $\mathrm{Ph} . \mathrm{D}$ degree. He has published several papers in National \& International Journals \&Conferences. He is the life member of FIETE, IE \&MISTE.

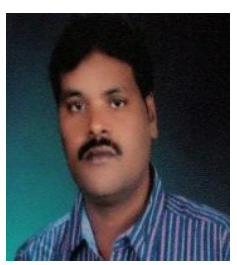

K Y Srinivas obtained B.Tech degree in Electronics and communication engineering from JNTUk College of engineering in 1994. He received his M.Tech degree from JNTUK Kakinada. $\mathrm{He}$ is currently working as Associate Professor \& In-Charge HOD, Department of ECE in Mallareddy Institute of Technology and Science 